\title{
OPPORTUNITIES OF HYDRAULICS VERSUS ELECTROMECHANICAL DRIVES
}

\author{
Dr. Ing. Peter WÜSTHOF \\ Vice President \\ Technology and Development \\ System Technology \\ Mannesmann Rexroth $\mathrm{GmbH}$ \\ P.O.Box 3 20, D-97813 Lohr, Germany
}

\begin{abstract}
" Opportunitics of Hydraulics versus Elcctromechanical Drives"

Electromechanical and hydraulic linear drives (loop structures). Hydraulic linear drives in machine tools, presses, plastic machiness and steel mills. Hydraulic rotary drive (secondary control) versus electrical rotary drive.
\end{abstract}

\section{KEY WORDS}

Hydraulic and Electromechanical Drives

\section{INTRODUCTION}

1. Electromechanical and hydraulic linear drives

In industrial applications, the electromechanical linear drive usually consists of an $\mathrm{AC}$ servo motor and a ball screw. This drive is well suited for position and speed control on account of its stiffness and linearity.

The positition and speed controllers have a generally proportional characteristic, with an integral derivative being superposed in the speed controller. Through its simple structure and clear distinction of the interfaces on the command and the feedback side, the electromechanical linear drive for position and velocity control is technically a strong concept.

The hydraulic linear drive comprises a simple cylinder generally of the differential type. This drive is compact and easy to control by means of appropriate black and white valves, proportional- or servo valves. The hydraulic linear drive presents the disadvantages of nonlinear characteristics low stiffness and low damping. However this disadvantages can be partially compensated by intelligent control concepts. Control electronics are therefore of vital importance to hydraulic linear drives. A position controller for a hydraulic drive which is suitable for standard applications is shown in (Figure 1).

The following controller functions can be achieved:

-Linear gain characteristic curve

-More-gradient gain characteristic curve

-Forward/backward alignment

-Change of gain possible by the NC program

-Fine positioning

-Residual voltage principle

-Compensation for null point errors

-Status fecdback

-Command value implementation

-Limitation of the actuating variable by the NC program -Position-dependent deceleration

The features of the double lined functions can be controlled via the NC program. The status controller using feed back of speed and acceleration to increase loop gain is optional. 


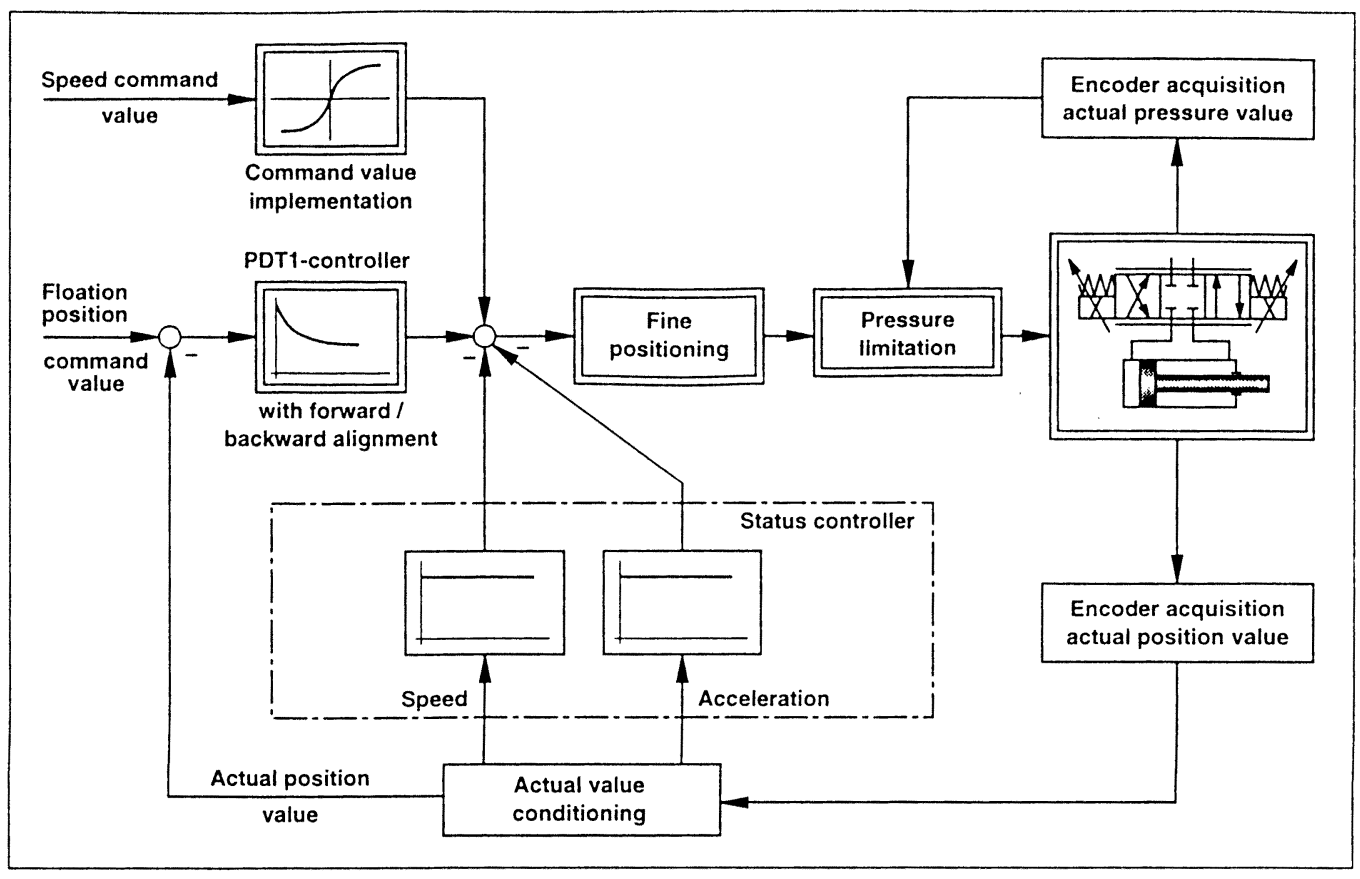

Figure 1.Position controller

\section{Machine tools without hydraulics?}

Modern standard machine tools and transfer machines are electrically driven. The main rotary drive always were electric and will remain so. For many years electrics offered the better overall concept - one that would be termed a functional system solution including the master control system.

By contrast hydraulics was only available as a fragmentary component solution. The opportunities on the market were therefore restricted. Today, hydraulics too can offer a system solution, though there are disadvantages in terms of position and velocity control an account of the lower stiffness and damping properties. The question of load stiffness, for example, especially in the presence of changing forces (dynamic load stiffness), is crucial in determining the quality of the surface finish and the dimensional accuracy of a workpiece. Even by applying advanced control technology, the dynamic load stiffness of hydraulics is low by factor 3 to 4 than that of the electromecha-
There are even signs of new beginnings for hydraulics in transfer machines. The system plan of a hydraulic NC linear drive for a car manufacturing plant is shown in (Figure 2).

The hydraulic axis is controlled at A and B port by a proportional valve making use of the return oil flow. In this way a sufficient stiffness and loop gain is achieved, which allows an excellent dynamic position accuracy. Control electronics and absolute position measuring device are integrated in the axis. The complete system can be tested and optimized on a test bench before being commissioned.

Thanks to system engineering solutions integrating electronics into hydraulics, through mastery of control engineering and clear definition of interfaces with the machine control, but above all thanks to the ruggedness, ease of maintenance and the favourable price/performance ration, the hydraulic linear drive is back in machine tool business again today. nical drive.

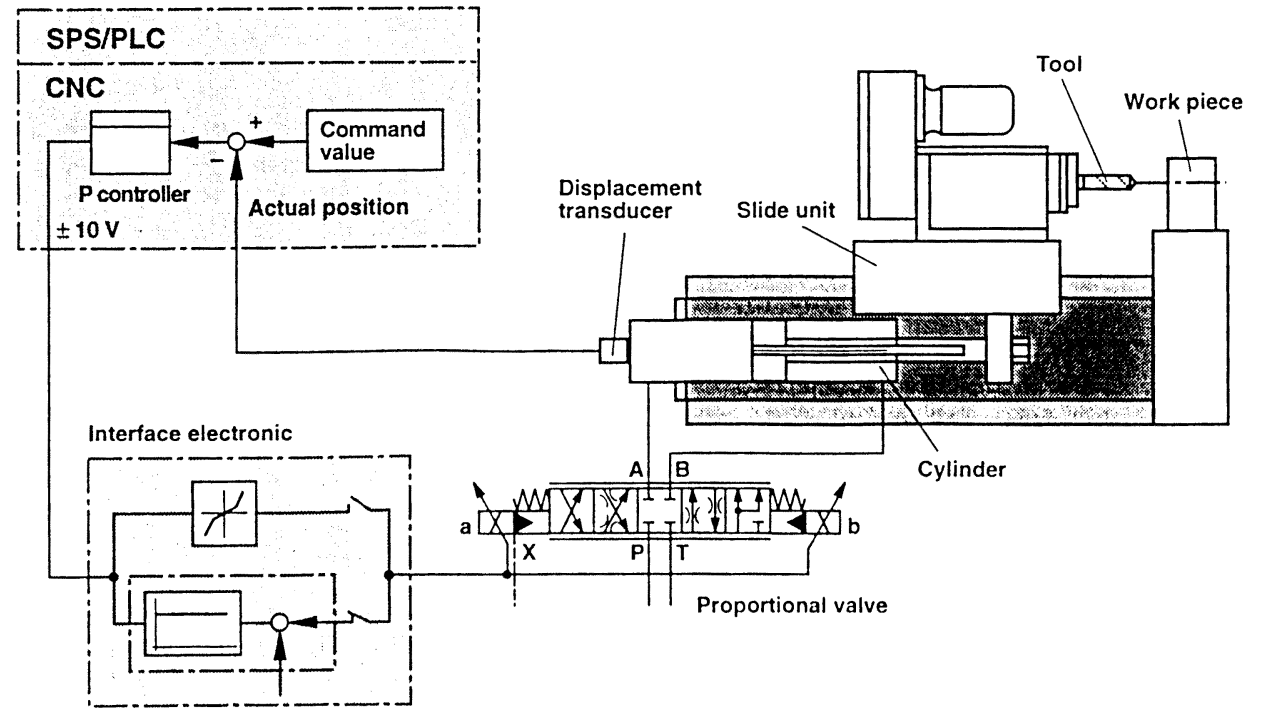

Figure 2. Hydraulic NC lincar axis 


\section{Presses - an application where hydraulics holds way}

Non-cutting machine tools remain an area where hydraulics predominates. There is no risk of substitution here. In presses, the strengths of hydraulics are obvious. High power density, ruggedness, compact build, cxcellent controllability of position, velocity, force or pressure, motion synchronization - all these will not be replaced by alternative drives in the foreseeable future. Even new markets can be penetrated with these technical attributes. An exeample of this is internal high pressure forming (IHPF), as shown in Figure 3.

Previously, complicated hollow parts, such as the exhaust train or strut profiles for vehicles had to be formed as separate parts that were then machined by cutting and welded together. This involved quite a number of individual process steps. IHPF makes it possible to manufacture the parts in one single process. The core of such a plant is the pressure intensificr which generates between $2(0)(0)$ and 6000 bar watcr pressure from a hydraulic input pressurc of around 300 bar. Starting with a simple picce of tubc, this process can form a complcx part by application of pressures up to 6000 bar. Weight savings of $40-70 \%$, smooth, high-quality surfaces textures, savings in materials and energy, high strength through cold hardening, and the observance of close tolcrances are only a few of the advantages provided by this process. The decisive factor is strict adherence to a pressure progression curve while the material is in flux. A hydraulic control loop with pressure feedback offers ideal conditions for this purpose.

The pressure controller is activated via the NC program and allows the following functions:

-Differential pressure evaluation

-PI-controller with DT1 pressure feedback

-Cut in of I-component via window

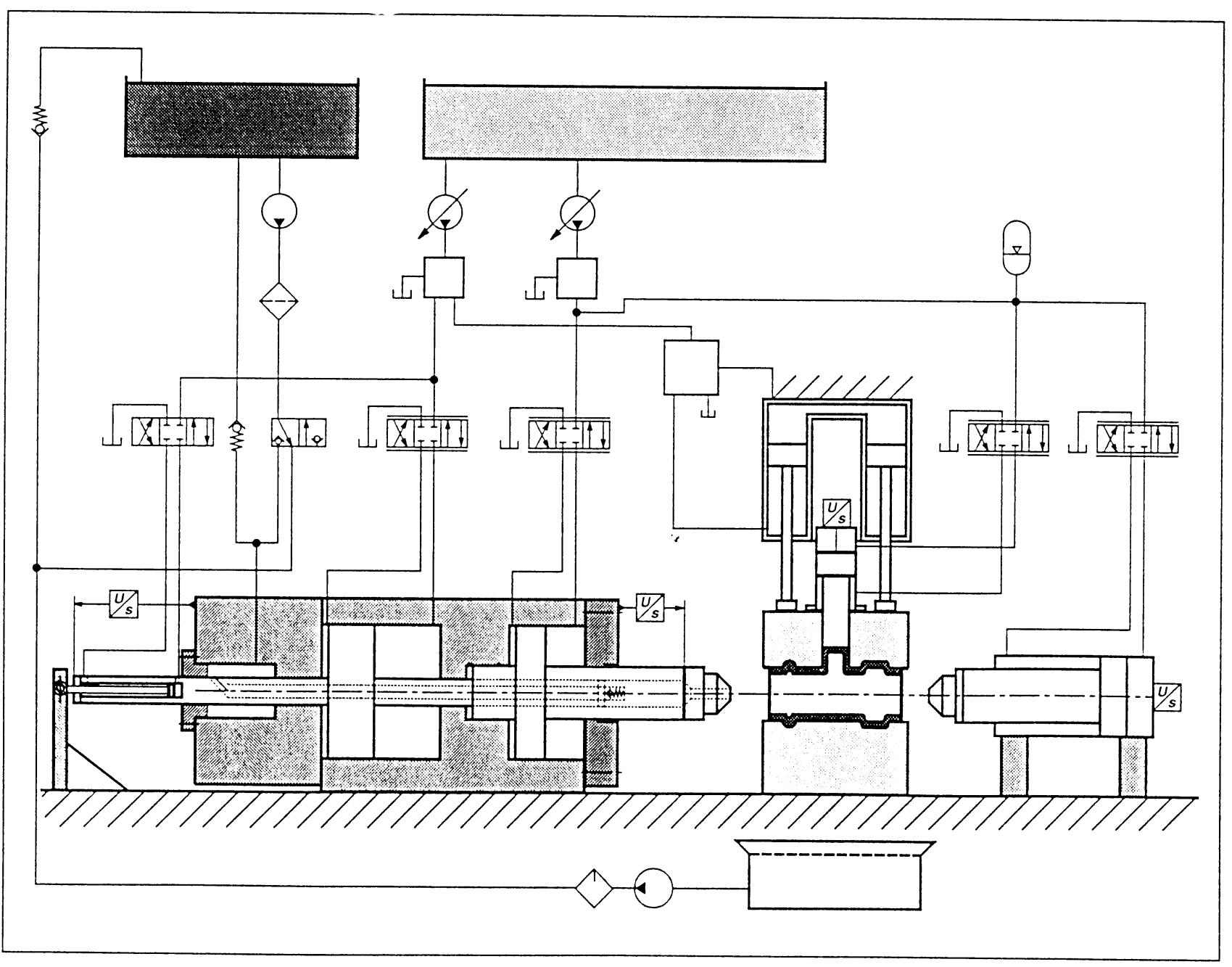

Figure 3. Internal high pressure forming 
4. Electric plastics processing machine just around the cormer?

Will the electric drive crode the predominant position of the hydraulic plastics processing machine?.The hydraulic drive for plastics processing machines is still the corc business in industrial fluid technology. Except for mobile machinery there is no other comparable large-series outlet for hydraulics. At the EMO 95 in Düsseldorf, an increasing number of electrically driven plastics processing machines were being presented. The promotion concepts and sales arguments, through slanted for strong public appeal are nevertheless correct. Low energy consumption through sequenceable single axis drives (E-motor, toothed belt plus ball screw), environmental compatibility and low noise generation are all arguments capable of comvincing even non specialists.

Besides position and velocity controls, plastics processing machines need pressure controls for the injection unit. The material to be injected can only be processed to the desired quality if the pressure is controlled quantitatively. Pressure control comparing the actual value with the command value are features at which hydraulics, by its very nature, excels. In the electromechanical drive, pressure can only be generated indirectly, taking a detour via force (force pickup) ot the current consumption of the electric motor.
The common method of controlling hydraulic axes by means of proportional and high-response valves docs meet the technical requirements, but also involves power losses. These power losses can be eliminated when pressure and flow are controlled directly by the pump. Consequently, the pump control as shown in (Figure 4) is an effective instrument if it succeeds in meeting the technical demands, i.e. of conrolling force, velocity and position to the same level as does a throttle control.

A pressure sensor feeds back the load pressure. In addition, position transducers provide a feedback signal for the pump swivel angle and the position of the control valve. The differential signal, for pressure or flow, obtained from the command/actual value comparison is used as the command value to govern the fast control valve on the pump. Only one control loop at a time can be active, either the pressure or the flow loop. Electronically, the control is achieved by a minimum value generator. Depending on the working cycle, the energy consumption improves by up to $20 \%$ and thus comes close to that of electrical machines. The lower level of heat generated by the pump control means that an oil cooler can generally be dispensed with.

The plastics processing machine still has good prospects for the future. Mixed drives are also conceivable. The rotary drive for the injection process could in future be powered by electric motors.

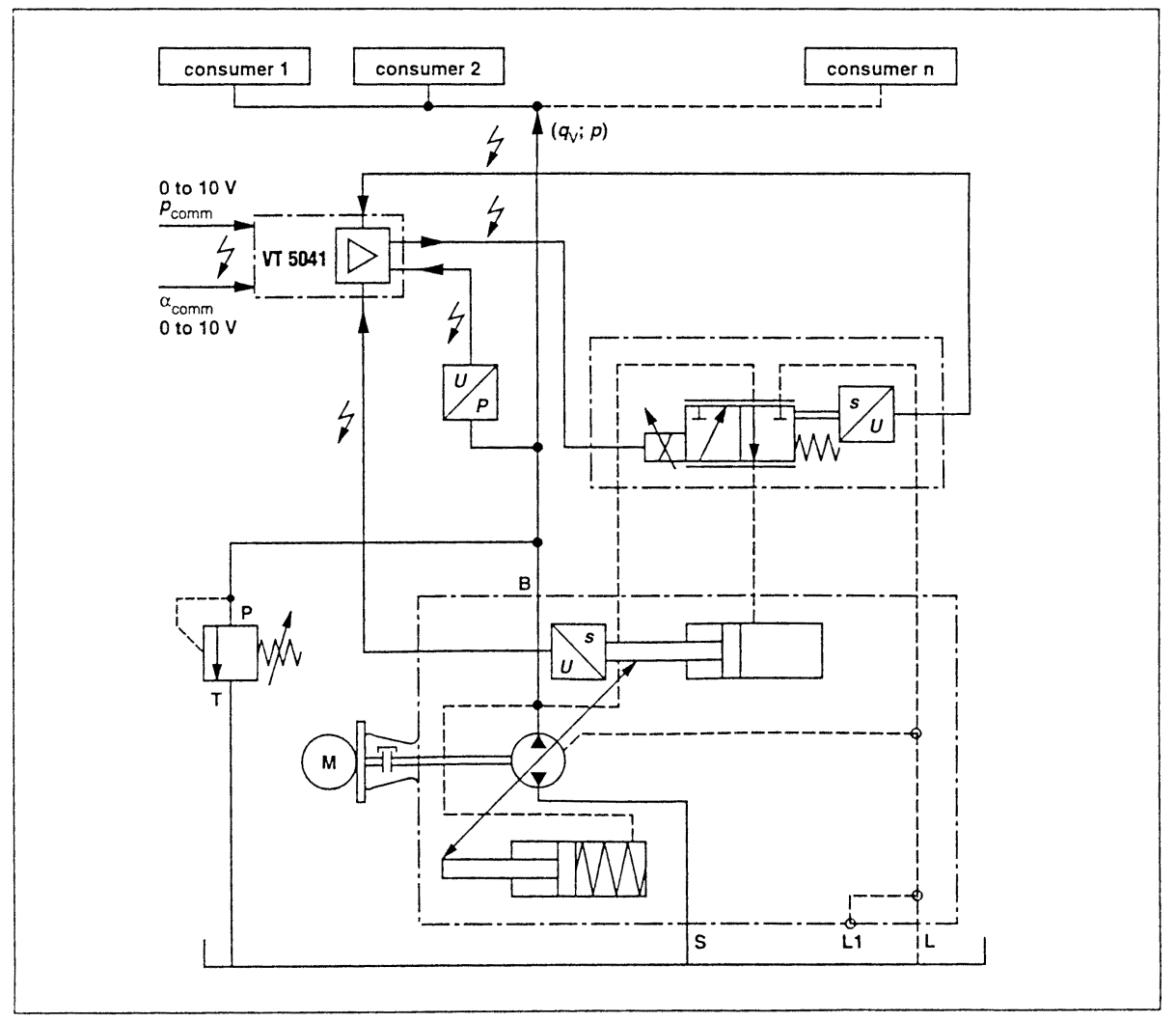

Figure 4. Pressure and flow control through axial piston pump 
5. New hardware and software concepts for hydraulic drives in stecl mills

Technological further development and automation in the various sectors of industry require more and more the use of high performance controls - also in the field of stecl mill technology.

A typical application is the hydraulic oscillation drive for chill moulds in continous casters. The quality improvements required from continously cast products have made it necessary to develop new concepts in continous casting. A conventional reciprocating table comprises of an electro-mechanical system, where the rotation of a RPM controlled electric-motor is translated by shafts and eccentrics into the up and down movement of the reciprocating table. The hydraulic drive, which has advantages over the electro mechanical drive, is shown in (Figure 5). Due to the direct connection via cylinders higher dynamic and stiffness have been achieved, which allows oscillation frequencies of $5 \mathrm{~Hz}$ and more. Of note is that the resonance mould works in the natural frequency band of $6-7 \mathrm{~Hz}$ and so lower powers are required.

A further advantage is the compactness of the hydraulic system. This is of particular importance when converting existing systems. Two servo cylinders are to be found directly on the mould frame to the left and right of the strand. The connections to the hydraulic system are via clean break quick relcasc couplings, utilised when changing moulds. The drive consists of two synchronous cylinders with hydrostatic pocket bearings, the features of which are tolerance to side loads and very low friction. Integrated into the cylinder are the positional transducers. These are therby protected from the surrounding environmental conditions. Directly mounted onto the cylinder is the manifold which comprises of the servo valve and relevant pressure relief and isolator valves. The possibility of measuring the pressure within the cylinder chambers is provided and can be used for example to determine the friction in the mould.

The position of the cylinder is obtained via the inductive transducers as a voltage signal and passed onto the digital controller via the measuring amplifiers. In the controller not only the command and actual values are compared, but also the cylinder synchronisation is monitored. The control signal passes via the valve amplifier to the servo valve.

The various operating parameters such as stroke, curve form and casting velocity dependent frequency are stored by the software as data sets on PC. These can be called up as required to suit the type of steel which is to be cast. The programme generates the command value curve and passes the data to the real time processor card, which takes over the control function.

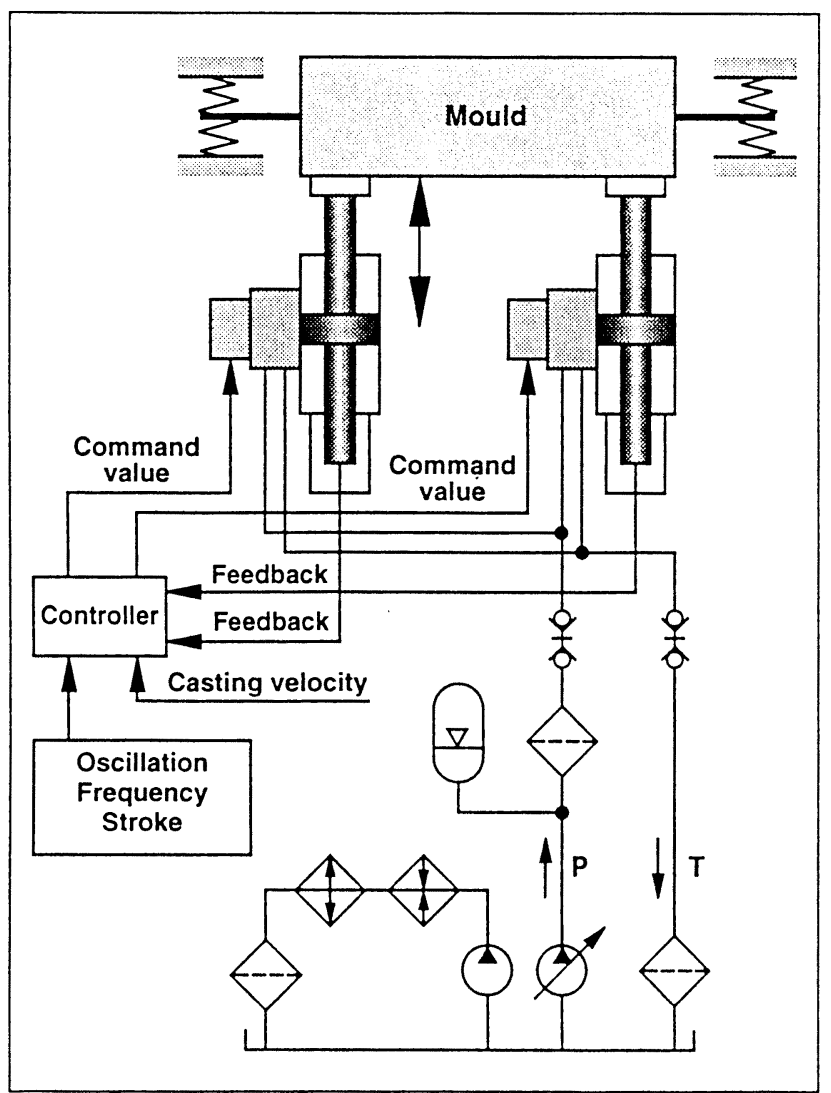

Figure 5. Hydraulic oscillation drive for chill moulds 
6. Secondary controlled hydrostatic drive, a contender in electrical rotary drives?

A good $90 \%$ plus of all industrial drives use cylinders, i.c. they are linear drives. As opposed to the widespread mobile hydraulic travel drives, purely rotary hydraulic motors are seldom found in the industrial sector. When they do occur, they are relegated to subordinate tasks. Main rotary drives in almost all power classes are the domain of the electric motor.

The electric motor will continue to be unassailable in the future if confronted with conventional hydraulic technology. However, the hydraulic rotary drive - a development that has in the meantime gone into regular series production - could become known by the name of the "secondary control".

The secondary unit operates at constant pressure and reaches the prescribed torque and speed by matching of the volume displaced per stroke. The control structure of a hydraulic secondary unit is practically identical with the control structure of an electrical DC machine. The swivel angle feedback of a hydrostatic axial piston unit corresponds to the current feedback of an electrical DC machine. As regards the speed feedback, there is no difference. The advantages of the secondary control are: -rotary drive with high dynamic response -reversing mode in open or closed circuit (four-quadrant operation)

-energy recovery and energy accumulation

-speed, position or torque loop with precision control -throttle-free coupling and energy transfer for any number of units

-low power losses, especially under partial load conditions.

Generally speaking, the secondary control is eminently suitable for use in testing technology. (Figure 6) shows a twin-axis torsion testing rig for engines. The test rig is designed according to the secondary control principle. A quasi-constant operating pressure is supplied by a pressure controlled pump. The secondary unit, working in motor mode, has an electronic speed control loop by adjustment of the swivel angle. To load the test specimen, the constant operating pressure allows a torque to be preselected by means of an open or closed loop swivel angle control on the secondary unit working in pump mode.

Hydraulic torsion-stressing of the test specimen considerably reduces the primary input energy as compared with comventional drive systems. The required primary power depends on the system design but is generally $30 \%$ lower than the torsion stressing power.

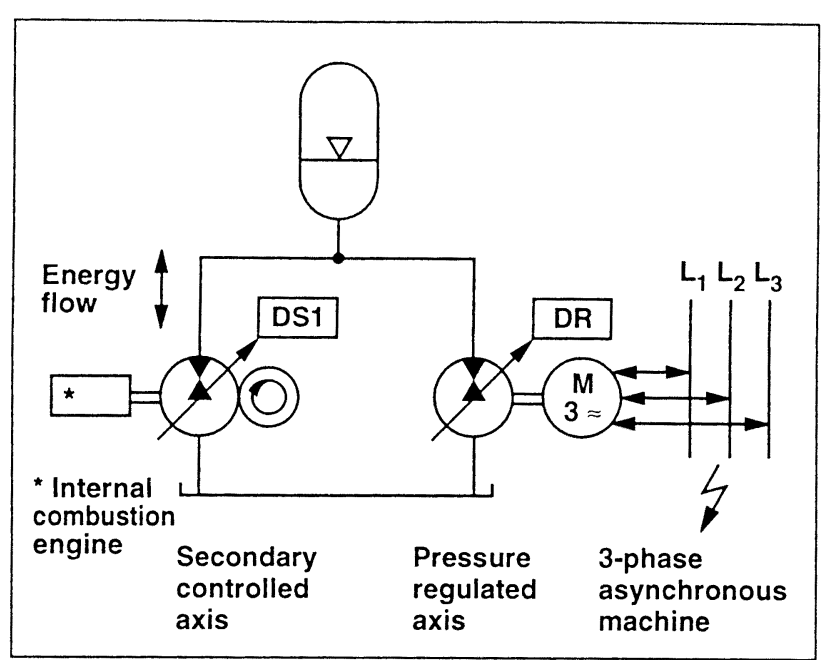

Figure 6. Test rig with secondary control

\section{Future prospects for hydraulics}

There is no question that the electromechanical drive is a concept that is accepted and cmployed worldwide as a highly developed system. By comparison, hydraulics has a lower acceptance rating in industrial applications. The hydraulic drive therefore needs new development impetus and examples of working installations with impeccable references. The market position for hydraulics will become all the better the sooner traditional weakness have been systematically and demonstrably eliminated. External leakage still continous to be found in hydraulic drives and controls. These leakages must be avoided. Manifolding of valves, properly laid piping and expert knowledge of appropriate sealing technologies are at the one time appropriate and indispensable ways of achicving this. Oil changes and disposal of hydraulic fluids and filter clements can be improved by employing fluids with a faster biodegradability rate and by regular conditioning of these fluids. Energy consumption and noise can be substantially improved by primary and sccondary measures. If all these conditions are met, the future will continue to offer great scope for the hydraulically driven machine. 